
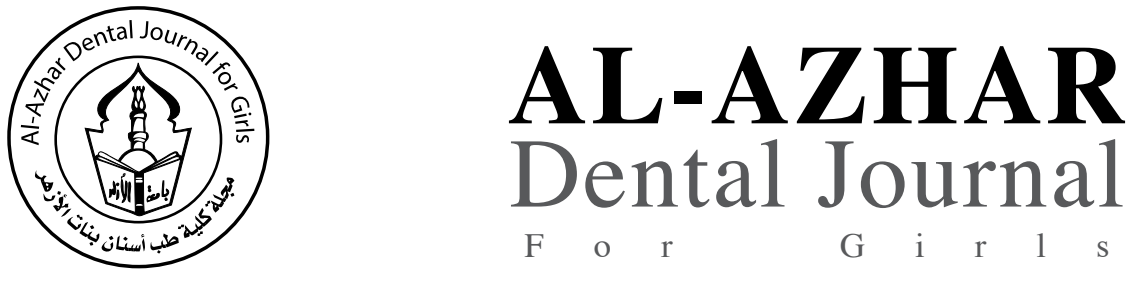

The Official Publication of The Faculty of Dental Medicine For Girls, Al-Azhar University Cairo, Egypt.

ADJ-for Grils, Vol. 3, No. 2, April (2016) - PP. 93:102

\title{
Effect of Laser Treatment, Self-Adhesive Resin Cement Brand and Thermocycling on Push out Bond Strength of Fiber Reinforced Post
}

\author{
Mariem Abu El-Nour ${ }^{(1)}$, Eman Essam ${ }^{(2)}$, Mohsen Nour Eldeen ${ }^{(3)}$ and Ahmed Abbas $^{(4)}$
}

Codex : 02/1604

dentaljournal.forgirls@yahoo.com

\begin{abstract}
The interface between the adhesive resin and fiber posts has an important role in their performance. However, It was found that the most frequent cause of their failure is debonding at the adhesive resin-dentin interface. The aim of the present study was to evaluate the effect of laser treatment: Erbium, Diode or no treatment; and two brands of self-adhesive resin cement: hydrophobic (Smartcem2) and conventional (Breeze); in addition to the effect of thermocycling on push out bond strength of Glassix fiber- reinforced composite post. A total of ninety- six freshly extracted natural human teeth were equally divided into three main groups after root canal treatment, decoronatin and post space preparation. Teeth of group 1 were treated with Er,Cr:YSGG laser, group 2 were treated with Diode laser, while the teeth of group 3 [control] received no laser treatment. Posts in half of the speciemens of the three groups were cemented with hydrophobic resin cement (Smartcem2) and the rest were cemented with conventional resin cement (Breeze). Samples of each group were further subdivided into two subgroups according to whether they were thermocycled or not. Three slices of $3 \mathrm{~mm}$ - thickness: cervical, middle and apical were prepared from each root. Then a push-out test was performed using universal testing machine at a strain rate of $0.5 \mathrm{~mm} / \mathrm{min}$. Data were analyzed using Unpaired t test. One-way analysis of variance (ANOVA) test was used to study the effect of different variables' interactions. This was followed by Tukey's post hoc test when a significant difference was detected. The significance level was set at $\mathrm{p} \leq 0.05$. The results revealed that the Er,Cr:YSGG $-2790 \mathrm{~nm}$ laser afforded greater bond strength than the diode laser. The hydrophobic self-adhesive resin cement demonstrated higher bond strength than the other brand. In addition, thermal stresses induced by thermocycling reduced the bond strength of Glassix fiber post.
\end{abstract}

1. Demonstrator, Endodontic department, Al Azhar University, Cairo, Egypt.

2. Assistant professor of Fixed Prosthodontics, Faculty of Dental Medicine, Al-Azhar University.

3. Professor, head of Endodontic department, Faculty of Dental Medicine, Al-Azhar University.

4. Associate Professor of Dental Laser Application, National Institute of Laser Enhanced Science (NILES), Cairo University. 


\section{INTRODUCTION}

Endodontically treated teeth, which have lost a large part of their structure and are subject to masticatory shearing forces most commonly need placement of a post in the root canal to provide retention for restoration. ${ }^{(1)}$ Application of cast metal posts were used for decades because of their high retention and adaptation, despite their high elastic modulus which is higher than both dentin and luting cement, and led to root fractures. ${ }^{(2)}$ On the other hand, when fiber posts were introduced, they gained great popularity, not only because of their elastic modulus, which is matching with both dentin and resin cement, but also because of their elasticity, high tensile strength, low electrical conductivity, resistance to solubility or corrosion and resistance to biochemical degradation. Furthermore, it is easy to remove it from the root canal. This is considered an advantageous for improving the performance of the restoration with decreasing the risk of root fractures. The longevity of those restorations depends on many factors such as effectiveness of the bonding between the post, dentin, the adhesive resin and its durability. The bonding between FRC posts and the root canal dentin wall can improve the distribution of forces generated along the roots; consequently reduce the stress generated on root canal walls, thereby strengthening the remaining tooth structure without the risk of fracture. The interface between the adhesive resin and FRC posts has an important role in the performance FRC post retained restorations. However, the most frequent cause of failure of FRC post restoration is debonding at the adhesive resin-dentin interface. Preparation of the post space results in a thick smear layer production at the root canal wall leading to increasing the leakage and obstruction of the dentinal tubules. This prevents the effective bonding, therefore, the root canals need to be effectively cleaned before post cementation. Previously, several irrigating solutions were used as pre-treatment agents before posts' cementation, but recently, pretreatment with laser system was introduced. The ER,CR:YSGG laser pre-treatment improved the FRC post bonding to the root canal dentin, because of its high absorption by water and hydroxyapatite. The absorbed energy cause evaporation and micro-explosions and these ablate the hard tissue through thermo-mechanical ablation. ${ }^{(3)}$ The effects of the heat produced by lasers during thermomechanical processes might appear as liquefaction, recrystallization, changes in the size of mineral particles, carbonization and formation of small cracks, which can influence the strength of the bond between the dentin matrix and the adhesive system. $^{(4)}$ In recent years, the Er,Cr: YSGG laser has attracted a lot of attention. This laser can be effectively used to cut enamel, dentin, cementum and bone when used with water and air as cooling agents. ${ }^{(5,6)}$ Studies by Hossain et al, have shown that in laser-irradiated dentin surfaces the orifices of the dentinal tubules are large and irregular, and no smear layer or thermal changes such as fusion and carbonization are visible. ${ }^{(7)}$ In contrast, Yamazaki et al, reported that high-power laser irradiation led to fusion, carbonization and formation of big cracks on the root canal walls. ${ }^{(8)}$ In addition to post type and cleaning of the root canal, the cement type affects also post retention. The choice of resin cements that relay on the use of etch and rinse adhesives or self-etching adhesives or self-adhesive resin cements. Proper mechanical properties are essential for adequate post retention. The durability and longevity of resin bonds are mostly tested by long-term water storage and thermal cycling. ${ }^{(9)}$ The combining effect of laser treatment of root canal dentin, self-adhesive resin cement type and thermocycling should therefore be evaluated. The integrity of this bond should be also tested.

The aim of the present study was to evaluate the effect of laser treatment: Erbium, Diode or no treatment; and two brands of self-adhesive resin cement: hydrophobic (Smartcem2) and conventional (Breeze); in addition to the effect of thermocycling on push out bond strength of Glassix fiber- reinforced composite post. 


\section{MATERIALS AND METHODS}

A total of 96 sound human maxillary central incisors without any cracks or carious lesions, confirmed by evaluation with a dental explorer and under a magnifying loop, were used in the present study. The teeth had been extracted due to periodontal and orthodontic reasons and were stored in saline solution of $0.9 \%$ concentration at room temperature. Teeth with any canal obstruction or with working lengths less than $14 \mathrm{~mm}$ were excluded from the study. The teeth were decoronated $1 \mathrm{~mm}$ coronal to the cementoenamel junction after removing all the calculi and debris from the root surface using hand scalers. Micracut 150 precision cutter (Metkon instrument Ltd, Bursa, Turkey), under water coolant was used for decoronation. The canals were shaped and prepared $1 \mathrm{~mm}$ short of the apex. Firstly treated with manual K-files (Dentsply Maillefer, Ballaigues, Switzerland) from size 0.6 to 25 , in order to obtain an initial glide path, and then prepared by rotary Ni-Ti Pro-taper mounted at c smart 3 motor (Forshan Coxo medical instrument )with instrument S1, S2, F1, F2, and F3 (DentsplyMaillefer, Ballaigues,Swiss) and $2.5 \%$ sodium hypochlorite for rinsing. The root canals were dried with paper points (Meta Biomed Co. LTD, Baotou, China). They were then obturated with gutta-percha (Dentsply-Maillefer, Ballaigues, Swiss) and resin sealer (Metabiomedco.LTD). The specimens were then embedded in a mold filled with acrylic resin (Acrostone,Idustrial area El-Salam city, Egypt).

Each prepared root was fixed vertically in the acrylic block using a vertical holding device (Isoparallelometro motorizzato,silfradent,Itally). $10 \mathrm{~mm}$ of each canal length was prepared using no. 3 and no.2 gates glidden drills with rubber stoppers (Dentsuply/Maillefer,Ballaigues,Switzerland). Size 2 Galssix post drill of $1.2 \mathrm{~mm}$ diameter was mounted at low speed hand piece (c smart 3 endomotor). The posts were cleaned with $70 \%$ ethanol and dried with compressed air. The samples were then randomly divided into three groups. The canals in group 1 (Er,Cr:YSSG laser group) were first irradiated with the Er,Cr:YSGG laser (Waterlase, Biolase Technology, Bayern, Germany) using an output power of $1.5 \mathrm{~W}$ and $50 \%$ air and water level. The laser tip was changed after every four specimens. Samples of group 2 were irradiated with Diode laser (BIOLASE, WaterLase, EPIC, ComfortPulse, EzTips) using an output power of $1.5 \mathrm{~W}$. In group 3 , no laser treatment was used. Half of the samples of each group were cemented with hydrophobic (Smartcem2) resin cement and the other half were cemented with conventional (Breeze) resin cement using load applicator. The cements were applied to the canals and posts. Smartcem2 is Self adhesive resin cement, dual cure, fluoride-releasing and hydrophobic in nature. This hydrophobic character minimizes post-cure water sorption, solubility and hygroscopic expantion.

It contains Urethane Dimethacrylate; Di and Tri-Methacrylate resins; Barium Boron FluoroAlumino-Silicate glass, Organic Peroxide Initiator; Camphorquinone(CQ), Photoinitiator: phosphene oxide photoinitiator, Accelerators: Butylated hydroxy toluene, UV stabilizer, titanium dioxide, iron oxide, hydrophobic amorphous silicon dioxide. Breeze is Self adhesive resin cement, dual cure, fluoride-releasing, conventional in nature. It contains Bis-GMA: bisphenol-A-diglycidyl methacrylate; UDMA: urethane dimethacrylate; TEGDMA: triethyleneglycol dimethacrylate; HEMA: 2-hydroxyethyl methacrylate; 4-MET: 4-methacryloxyethyl trimellitic acid, Silane treated barium glass, silica (amorphous), Ca-Al-F-silicate. It consists of specially designed multifunctional, phosphoric acid modified methacrylate monomers. These monomers form a highly cross-linked cement matrix during radical polymerization and the phosphoric acid groups contribute to self adhesion. 
After posts' seating, light curing was performed for 30 seconds (Aventé LED Curing Light). After cementation, all samples were then water-stored for three months (distilled water, $37^{\circ} \mathrm{C}$ ). Half of the specimens of each group were subjected to thermocycling (500 thermocycle shocks between water baths at $5 \mathrm{C}$ and $55 \mathrm{C}$, with a dwell time of 30 seconds) using thermocycling device. All the specimens were cut perpendicular to the long axis of the root under water spray using Micracut 150 precision cutter (Metkon instrument Ltd, Bursa, Turkey), so that each root yielded three dentin/ post segments (cervical, middle and apical), each with a thickness of $3 \mathrm{~mm}$. The push-out test was carried out using custom made loading fixture (push out jig attached to universal testing machine), ensuring that the coronal surface faced the jig and the post was centered over the hole of the jig. The push-out test was designed to apply a compressive load to the apical aspect of each slice via a $1 \mathrm{~mm}$ diameter cylindrical punch (plunger) mounted on a universal testing machine. A punch pin was positioned to contact only the post, without pressing the surrounding cement and/or root canal walls. The load was applied apico-coronally (towards the larger part of the root slice) on the apical surface of the slices with a crosshead speed of $0.5 \mathrm{~mm} /$ min until bond failure occurred (as manifested by the extrusion of the post segment from the root). After mounting in the custom made loading fixture, each sample was subjected to compressive loading via a computer controlled materials testing machine (Model LRX-plus; Lloyd Instruments Ltd., Fareham, UK) with a load cell of $5 \mathrm{kN}$. Data were recorded using computer software (Nexygen-MT; Lloyd Instruments) and loaded at a crosshead speed of $0.5 \mathrm{~mm} / \mathrm{min}$. The load was applied by 3 plungers of different sizes ( $1 \mathrm{~mm}, 0.75 \mathrm{~mm} \& 0.5 \mathrm{~mm}$ ) in an apical-coronal direction because of the convergence of the root canal sections (Cervical, middle and apical). The selected diameter of the plunger was positioned so that it only contacts the post to displace it downward. This way, it was assured that the overlaying root dentine was sufficiently supported during the loading process. The maximum failure load was recorded in $\mathrm{N}$ and converted into $\mathrm{MPa}$. The bond strength was calculated from the recorded peak load divided by the computed surface area [as calculated by the following formula (Lopes et al. 2010): Bond $=\mathrm{F} / \mathrm{A},[\mathrm{A}=(\pi \mathrm{h}(\mathrm{r} 1+\mathrm{r} 2)]$, where, $\pi$ is the constant 3.14, $\mathrm{r} 1$ apical radius, $\mathrm{r} 2$ coronal one, and $\mathrm{h}$ is the thickness of the sample in millimeters. Failure was manifested by extrusion of filling material and confirmed by sudden drop along loaddeflection curve recorded by computer software. Subsequent to the push-out test, the noticed failure modes were evaluated under a magnifying loop and classified into one of the following categories: (1) adhesive failure between resin cement and root canal dentin. (2) Cohesive failure within the resin cement, or (3) mixed failure. Unpaired t test was used. One-way analysis of variance (ANOVA) test was used to study the effect of different variables' interactions. This was followed by Tukey's post hoc test when a significant difference was detected. The significance level was set at $\mathrm{p} \leq 0.05$. Statistical analysis was performed with SPSS 16.0 (Statistical Package for Scientific Studies, SPSS, Inc., Chicago, IL, USA) for Windows.

\section{RESULTS}

\section{Effect of laser treatment:}

Comparing non laser treatment with erbium laser revealed greater mean push out strength value in erbium groups using both cements, with or without thermocycling. 
Table (1) Mean, standard deviation (SD) values and statistical significance of the difference between erbium laser and non-laser using unpaired t test.

\begin{tabular}{|c|c|c|c|c|c|c|c|}
\hline \multirow{2}{*}{ Cement } & \multirow{2}{*}{ Thermocycling } & \multicolumn{2}{|c|}{ Erbium } & \multicolumn{2}{|c|}{ Non-laser } & \multirow{2}{*}{ t value } & \multirow{2}{*}{ P value } \\
\cline { 3 - 7 } & & Mean & SD & Mean & SD & & \\
\hline \multirow{3}{*}{ Smart Cem 2 } & Thermocycling & 9.681 & 2.319 & 8.719 & 3.110 & 0.7439 & $0.4677^{\mathrm{ns}}$ \\
\cline { 2 - 7 } & Non -thermo & 11.400 & 2.309 & 10.044 & 1.904 & 1.3593 & 0.1929 ns \\
\hline \multirow{2}{*}{ Breeze } & Thermocycling & 5.830 & 1.063 & 3.467 & 1.083 & 4.6714 & $0.0003^{*}$ \\
\cline { 2 - 8 } & Non -thermo & 6.957 & 1.322 & 3.988 & 0.944 & 5.4831 & $>0.0001^{*}$ \\
\hline
\end{tabular}

* Significant, $n s=$ non-significant at $p<0.05$

Comparing non laser treatment with diode laser revealed greater mean push out strength value in diode groups using Breeze cements, with or without thermocycling, as well as in Smart Cem2 group without thermocycling.

Table (2) Mean, standard deviation (SD) values and statistical significance of the difference between diode laser and non-laser using unpaired t test.

\begin{tabular}{|c|c|c|c|c|c|c|c|}
\hline \multirow{2}{*}{ Cement } & \multirow{2}{*}{ Thermocycling } & \multicolumn{2}{|c|}{ Diode } & \multicolumn{2}{|c|}{ Non-laser } & \multirow{2}{*}{ t value } & \multirow{2}{*}{ P value } \\
\cline { 3 - 7 } & & Mean & SD & Mean & SD & \\
\hline \multirow{3}{*}{ Smart Cem 2 } & Thermocycling & 7.412 & 0.893 & 8.719 & 3.110 & 1.2118 & $0.2432^{\mathrm{ns}}$ \\
\cline { 2 - 8 } & Non -thermo & 10.778 & 0.814 & 10.044 & 1.904 & 1.0634 & $0.30344^{\mathrm{ns}}$ \\
\hline \multirow{2}{*}{ Breeze } & Thermocycling & 4.862 & 0.965 & 3.467 & 1.083 & 2.8851 & $0.0108^{*}$ \\
\cline { 2 - 8 } & Non -thermo & 7.548 & 1.196 & 3.988 & 0.944 & 7.0094 & $>0.0001^{*}$ \\
\hline
\end{tabular}

* Significant,$\quad n s=$ non-significant at $p<0.05$

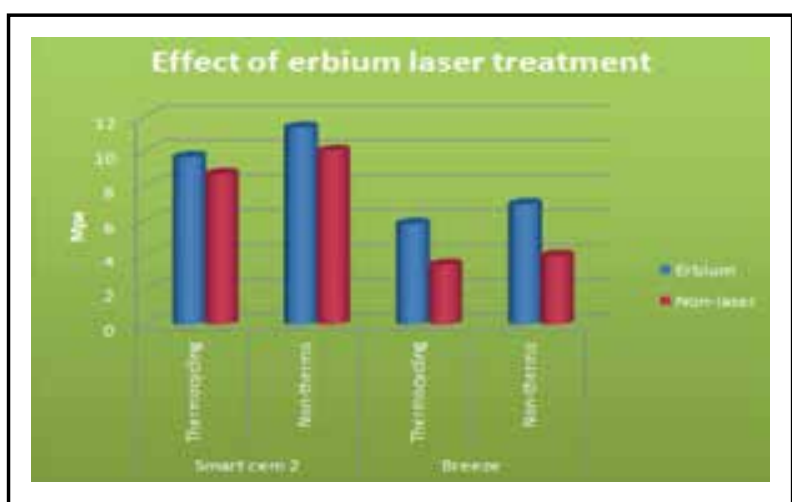

Fig. (1) Column chart representing mean values of push- out strength in erbium laser and non-laser groups.

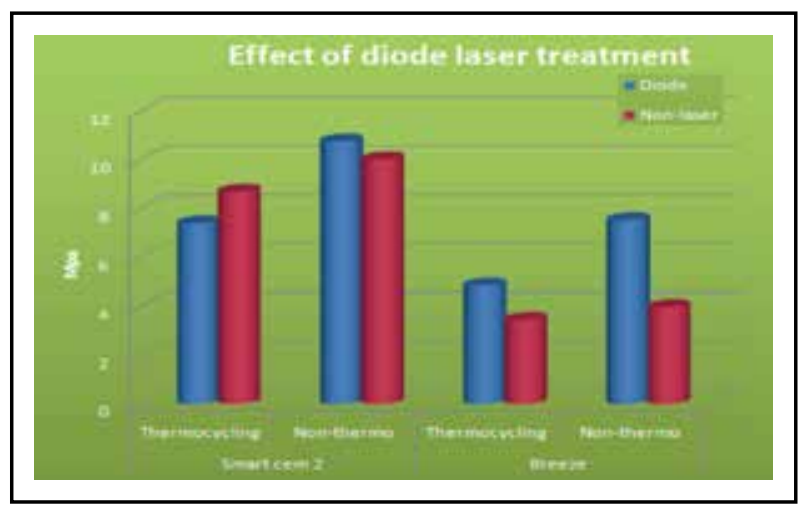

Fig. (2) Column chart representing mean values of push- out strength in Diode laser and non-laser groups. 


\section{Effect of laser type:}

Comparing erbium laser treatment with diode laser revealed greater mean push out strength value in erbium groups using Smart Cem2, with or without thermocycling, as well as in Breeze cements with thermocycling.

Table (3) Mean, standard deviation (SD) values and statistical significance of the difference between diode laser and erbium laser using unpaired t test.

\begin{tabular}{|c|c|c|c|c|c|c|c|}
\hline \multirow{2}{*}{ Cement } & \multirow{2}{*}{ Thermocycling } & \multicolumn{2}{|c|}{ Erbium } & \multicolumn{2}{|c|}{ Diode } & \multirow{2}{*}{ t value } & \multirow{2}{*}{ P value } \\
\cline { 3 - 7 } & & Mean & SD & Mean & SD & & \\
\hline \multirow{3}{*}{ Smart Cem 2 } & Thermocycling & 9.681 & 2.319 & 7.412 & 0.893 & 2.7392 & $0.0146^{*}$ \\
\cline { 2 - 7 } & Non -thermo & 11.400 & 2.309 & 10.778 & 0.814 & 0.7622 & $0.4570^{\mathrm{ns}}$ \\
\hline \multirow{2}{*}{ Breeze } & Thermocycling & 5.830 & 1.063 & 4.862 & 0.965 & 2.0227 & $0.0601^{\mathrm{ns}}$ \\
\cline { 2 - 8 } & Non -thermo & 6.957 & 1.322 & 7.548 & 1.196 & 0.9945 & $0.3348^{\mathrm{ns}}$ \\
\hline
\end{tabular}

* Significant, $n s=$ non-significant at $p<0.05$

\section{Effect of cement type:}

Comparing Smart Cem2 with Breeze cement revealed greater mean push out strength value in Smart Cem2 groups, with or without thermocycling and in all types of laser and non-laser treatment.

Table (4) Mean, standard deviation (SD) values and statistical significance of the difference between smart cem2 and breeze cements using unpaired t test.

\begin{tabular}{|c|c|c|c|c|c|c|c|}
\hline \multirow{2}{*}{ Laser type } & \multirow{2}{*}{ Thermocycling } & \multicolumn{2}{|c|}{ Smart Cem 2} & \multicolumn{2}{|c|}{ Breeze } & \multirow{2}{*}{$\mathrm{t}$ value } & \multirow{2}{*}{$P$ value } \\
\hline & & Mean & SD & Mean & SD & & \\
\hline \multirow{2}{*}{ Erbium } & Thermocycling & 9.681 & 2.319 & 5.830 & 1.063 & 4.5288 & $0.0003^{*}$ \\
\hline & Non -thermo & 11.400 & 2.309 & 6.957 & 1.322 & 5.0096 & $>0.0001 *$ \\
\hline \multirow{2}{*}{ Diode } & Thermocycling & 7.412 & 0.893 & 4.862 & 0.965 & 5.8184 & $>0.0001 *$ \\
\hline & Non -thermo & 10.778 & 0.814 & 7.548 & 1.196 & 6.6979 & $>0.0001^{*}$ \\
\hline \multirow{2}{*}{ Non-laser } & Thermocycling & 8.719 & 3.110 & 3.467 & 1.083 & 4.7844 & $0.0002 *$ \\
\hline & Non -thermo & 10.044 & 1.904 & 3.988 & 0.944 & 8.5490 & $>0.0001^{*}$ \\
\hline
\end{tabular}

* Significant at $p<0.05$

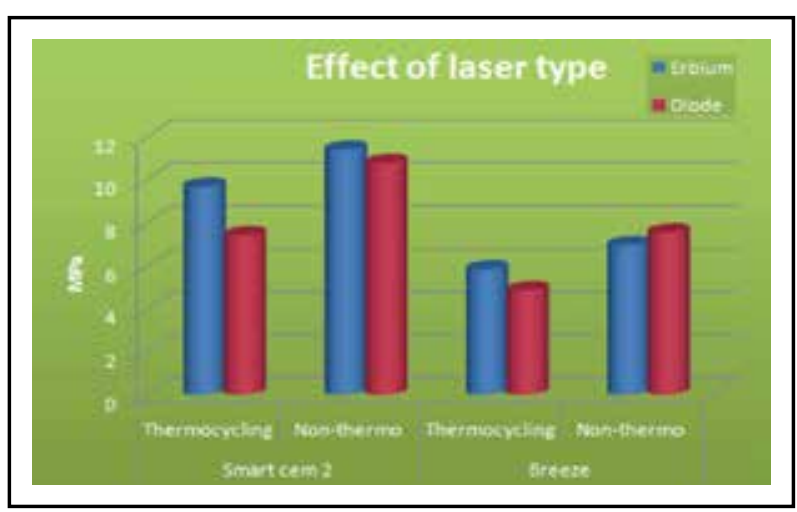

Fig. (3) Column chart representing mean values of push- out strength in Diode laser and erbium laser groups.

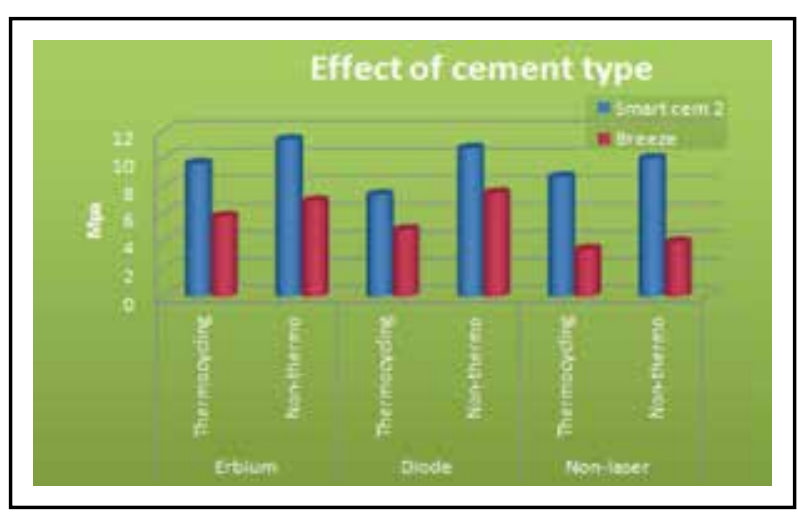

Fig. (4) Column chart representing mean values of push- out strength in smartCem 2 and breeze cement groups. 


\section{Effect of thermocycling:}

Comparing thermocycling with no thermocycling revealed greater mean push out strength value in nonthermocycling groups using both cements and in all types of laser and non-laser treatment.

Table (5) Mean, standard deviation (SD) values and statistical significance of the difference between Smart Cem2 and Breeze cements using unpaired t test.

\begin{tabular}{|c|c|c|c|c|c|c|c|}
\hline \multirow{2}{*}{ Laser type } & \multirow{2}{*}{ Cement type } & \multicolumn{2}{|c|}{ Thermocycling } & \multicolumn{2}{|c|}{ Non -thermocycling } & \multirow{2}{*}{$\mathrm{t}$ value } & \multirow{2}{*}{$P$ value } \\
\hline & & Mean & SD & Mean & SD & & \\
\hline \multirow{2}{*}{ Erbium } & Smart Cem 2 & 9.681 & 2.319 & 11.400 & 2.309 & 1.5759 & $0.1346^{\mathrm{ns}}$ \\
\hline & Breeze & 5.830 & 1.063 & 6.957 & 1.322 & 1.9931 & $0.0636^{\mathrm{ns}}$ \\
\hline \multirow{2}{*}{ Diode } & Smart Cem 2 & 7.412 & 0.893 & 10.778 & 0.814 & 8.3570 & $>0.0001 *$ \\
\hline & Breeze & 4.862 & 0.965 & 7.548 & 1.196 & 5.2435 & $>0.0001 *$ \\
\hline \multirow{2}{*}{ Non-laser } & Smart Cem 2 & 8.719 & 3.110 & 10.044 & 1.904 & 1.0901 & $0.2918^{\mathrm{ns}}$ \\
\hline & Breeze & 3.467 & 1.083 & 3.988 & 0.944 & 1.0879 & $0.2927^{\mathrm{ns}}$ \\
\hline
\end{tabular}

* Significant, $n s=$ non-significant at $p<0.05$

\section{Different variables' interactions:}

Tukey's post hoc test: means sharing a superscript letter are not significantly different.

Table 6 presents the push-out bond strength values in different parts of the roots in the experimental groups.

Table (6) Mean, standard deviation (SD) values and significance of the difference in push-out bond strength $(\mathrm{MPa})$ of the different interactions.

\begin{tabular}{|c|c|c|c|c|c|c|}
\hline Laser type & Cement type & Thermocycling & Mean & SD & F value & $P$ value \\
\hline \multirow{4}{*}{ Erbium } & \multirow{2}{*}{ Smart Cem 2} & Thermo & $9.681^{\mathrm{a}}$ & 2.319 & \multirow{12}{*}{17.107} & \multirow{12}{*}{$0.0001<*$} \\
\hline & & Non -thermo & $11.400^{\mathrm{a}}$ & 2.309 & & \\
\hline & \multirow{2}{*}{ Breeze } & Thermo & $5.830^{c}$ & 1.063 & & \\
\hline & & Non -thermo & $6.957^{\mathrm{b}, \mathrm{c}}$ & 1.322 & & \\
\hline \multirow{4}{*}{ Diode } & \multirow{2}{*}{ Smart Cem 2} & Thermo & $7.412^{\mathrm{b}}$ & 0.893 & & \\
\hline & & Non -thermo & $10.778^{\mathrm{a}}$ & 0.814 & & \\
\hline & & Thermo & $4.862^{\mathrm{c}}$ & 0.965 & & \\
\hline & Dited & Non -thermo & $7.548^{\mathrm{b}}$ & 1.196 & & \\
\hline \multirow{4}{*}{ Non-laser } & \multirow{2}{*}{ Smart Cem 2} & Thermo & $8.719^{\mathrm{a}, \mathrm{b}}$ & 3.110 & & \\
\hline & & Non -thermo & $10.044^{\mathrm{a}}$ & 1.904 & & \\
\hline & \multirow{2}{*}{ Breeze } & Thermo & $3.467^{\mathrm{d}}$ & 1.083 & & \\
\hline & & Non -thermo & $3.988^{\mathrm{d}}$ & 0.944 & & \\
\hline
\end{tabular}

* Significant at $p<0.05$ 


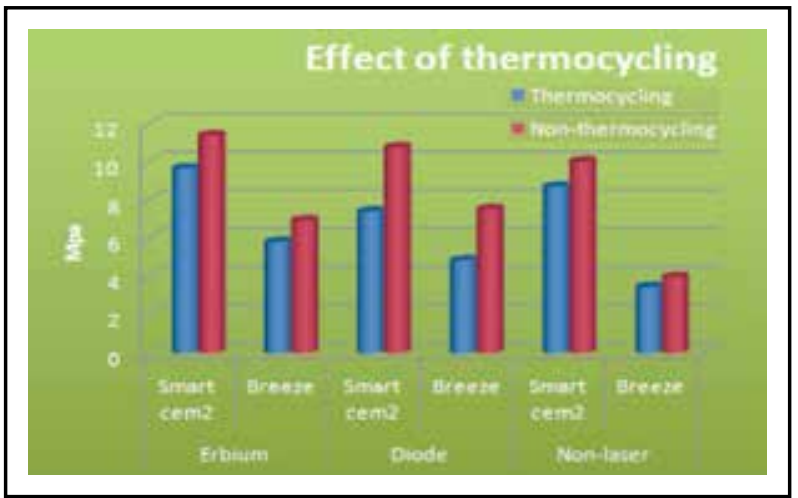

Fig. (5) Column chart representing mean values of push- out strength in thermocycling and non-thermocycling groups.

\section{DISCUSSION}

Endodontically treated teeth usually have a weak dentin structure because of extensive loss of tooth structure; therefore, such teeth need rehabilitation with the use of root canal posts. Fiber posts are extensively used for restoring excessive loss of tooth structure, in combination with adhesive materials, due to their esthetic results and elastic modulus which is similar to that of dentin. Thus creating homogenous stress distribution and decreasing the incidence of catastrophic root fracture. Also, they have the ability to bond to this substrate by the use of adhesive cements. ${ }^{(10)}$ Some lasers, such as the Er, CR: YSGG 2,790-nm laser and Diode lasers are used to alter dentin morphology. They were used with the aim of reducing the number of microorganisms within the root canal system and removing the smear layer to improve adhesion to the root canal walls. So it is possible that they influence the strength of the bond between post and root canal dentin. Using adhesive resin cements in luting fiber posts can improve the bonding of these restorations and improve their clinical performance. ${ }^{(1)}$ The present investigation was therefore set to compare the effect of Er,Cr:YSGG and Diode laser of post space surface treatments; Smartcem2 and Breeze as self adhesive resin cements and thermocycling on push out bond strength of fiber-reinforced post. Lin et al demonstrated that dentin hydroxyapatite particles and phases remain unchanged after laser

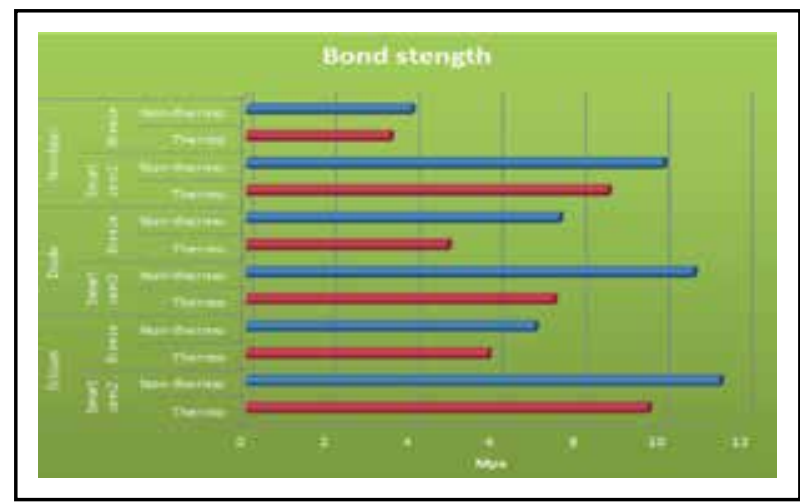

Fig. (6) Bar chart representing mean push-out bond strengths with different variable interactions.

irradiation. However, energy dispersive spectroscopy and atomic force Microscopy (AFM) phase images indicated a decrease in the organic content after laser irradiation, indicating thermal ablation of the organic component. ${ }^{(4)}$

The advantage of an Erbium wave is that it is well absorbed by water and dental hard tissues. Although dentin contains a high proportion of water, the depth is shallow for laser transmission. The strong absorption of water reduces the level of heat during tooth preparation. As water absorbs laser radiation better than dental hard tissue, it reduces the increasing temperature of the tissue during the preparation. Water reaches the boiling point and causes microexposure of the tooth. This action breaks up the surrounding tissue into small pieces and dissipates them at the same time. As this explosion occurs in water, it is so-called a preparation induced by water. Although most radiation is absorbed in water, a certain amount of heat transmission is unavoidable. Therefore, a water spray is used for cooling. When using an adequate water spray for this so called thermomechanical ablation, thermal damages of the surrounding tissue can be avoided. The water spray is not primarily a cooling system but necessary for the ablation process. Dentin treated by Erbium laser creates always a microretentive pattern, when the ablation threshold is passed. The settings (energy, frequency, fluence and pulse duration) of the laser became very important, if a good 
adhesion is desired. ${ }^{(12-14)}$ When used for disinfection of the root canals, lasers are known for their ability to remove smear layer and create acid-etched-like surface. ${ }^{(15)}$ The same results were found by Rebecca et al in (2014). ${ }^{(16)}$

Divito E. et al (2010), ${ }^{(17)}$ studied the effectiveness of the erbium YAG laser and new design radial and stripped tips in removing the smear layer after root canal instrumentation. The Er YAG showed significantly better smear layer removal than traditional syringe irrigation and no thermal effects or damage to the dentine surface was observed. Morphological analysis by scanning electron microscopy showed that irradiation of the root canal with the diode laser also resulted in removal of the smear layer, producing a clean and rougher surface with completely opened dentinal tubules, which might affect bond strength. It is moreover possible to affirm that the use of Er,CR:YSGG 2,790-nm laser endodontic fiber is safe for dental and periodontal tissues considering thermal effects as reported elsewhere about surgical use of this wavelength. ${ }^{(18)}$

Removing the smear layer that contains guttapercha remnants, microorganisms, and infectious dentin is necessary for the penetration of the adhesive system and resin cement into the dentin tubules. $(107,108)$ Self-adhesive resin cements cannot completely remove the smear layer. ${ }^{(19,20)}$ This remaining smear layer could cause a lower bond strength for self-adhesive resin cements as compared with an etch and rinse adhesive system. The preliminary in vitro studies confirmed how difficult it is to completely eliminate the residual smear layer, particularly in the apical portion of the root. ${ }^{(21)}$

Maria Isabel et al (2013), ${ }^{(22)}$ studied the effects of 980-nm diode laser on the ultrastructure and fracture resistance of dentine with different irradiation energies (without irradiation, $1.5 \mathrm{~W} / 100 \mathrm{~Hz}$ and 3.0 $\mathrm{W} / 100 \mathrm{~Hz}$ ). The laser treatment did not alter the fracture resistance of roots treated with $1.5 \mathrm{~W} / 100$ $\mathrm{Hz}(246.3 \pm 29.5 \mathrm{~N})$ and $3.0 \mathrm{~W} / 100 \mathrm{~Hz}(215.3 \pm 25.1$ $\mathrm{N})$ laser power. The roots treated with $\mathrm{NaOCl}$ were more susceptible to fracture than those irrigated with water. The 980-nm diode laser altered the morphology of the dentine but did not affect the fracture resistance of the roots.

\section{CONCLUSIONS}

Within the limitations of this in vitro study, the following conclusions were drawn:

1. Laser treatment generally is an important factor in achieving improvement in bond strengths of fiber posts to root canal dentin.

2. The Er,Cr:YSGG $-2790 \mathrm{~nm}$ laser afforded greater bond strength than the diode laser.

3. The hydrophobic self-adhesive resin cement demonstrated higher bond strength than the conventional brand.

4. Thermal stresses induced by thermocycling reduced the bond strength of Glassix fiber post.

\section{Clinical Significance}

Using the glassix fiber-reinforced post with Erbium laser treatment of the root canal dentin; and cemented with hydrophobic adhesive resin cement would improve the bond strength of those restorations.

\section{REFERENCES}

1. Schwartz RS, Robbins JW. Post placement and restoration of endodontically treated teeth: a literature review. J Endod 2004; 30(5):289-301.

2. Zarone F, Sorrentino R, Apicella D. Evaluation of the biomechanical behavior of maxillary central incisors restored by means of crowns compared to a natural tooth: a 3D static linear finite elements analysis. Dent Mater 2006; 22 (11):1035-44.

3. Asnaashari M, Safavi N. Disinfection of Contaminated Canals by Different Laser. Wavelengths, while Performing Root Canal Therapy. J Lasers Med Sci 2013; 4(1):8-16.

4. Lin S, Pan D, Lin Q, Yin S, Chen D, Liu Q, Yu L, Lin Z. Evaluation of phase, microstructure and composition of human dentine after Er,Cr:YSGG laser irradiation. J Nanosci Nanotechnol 2011; 11(3):2421-2426. 
5. Eversole LR, Rizoiu IM. Preliminary investigations on the utility of an erbium, chromium YSGG laser. J Calif Dent Assoc 1995; 23 (12):41-47.

6. Eversole LR, Rizoiu I, Kimmel AI. Pulpal response to cavity preparation by an erbium, chromium:YSGG laserpowered hydrokinetic system. J Am Dent Assoc 1997; 128(8):1099-1106.

7. Hossain M, Nakamura Y, Yamada Y, Kimura Y, Matsumoto N, Matsumoto K. Effects of Er,Cr:YSGG laser irradiation in human enamel and dentin: ablation and morphological studies. J Clin Laser Med Surg 1999; 17(4):155-159.

8. Yamazaki R, Goya C, Yu DG, Kimura Y, Matsumoto K. Effects of erbium, chromium:YSGG laser irradiation on root canal walls: a scanning electron microscopic and thermographic study. J Endod 2001; 27(1):9-12.

9. Qualtrough AJE, Mannocci F. Tooth-colored post systems: a review. Oper Dent 2003; 28: 86-91.

10. Naumann M, Blankenstein F, Dietrich T. Survival of glass fiber reinforced composite post restorations after 2 yearsan observational clinical study. J Dent 2005; 33 (4) 305-12.

11. Alfredo E, Silva SRC, Ozório JEV, Sousa-Neto MD, BrugneraJunior A, Silva-Sousa YTC. Bond strength of AH Plus and Epiphany sealers on root dentine irradiated with 980 nm diode laser. Int Endod J 2008; 41:733-740.

12. Eun Mi Rhim, Sungyoon Huh, Duck Su Kim, Sun-Young Kim, Su-Jin Ahn, Kyung Lhi Kang,Park SH. Effect of the Er, Cr: YSGG Laser Parameters on Shear Bond Strength and Microstructure on Human Dentin Surface. Biomaterials - Physics and Chemistry 2011; (17):348-356.

13. Gutknecht, N. Proceedings of the 1st International Workshop of Evidence Based Dentistry on Lasers in Dentistry: Workshop in Vaals, the Netherlands; Feb. 2007. Quintessenz Verlags-GmbH, Berlin.
14. Gutknecht N. Kariologie und Kavitätenpräparation mit dem Er:YAG-Laser. LaserZahnheilkunde 2007; 2:75-83.

15. Israel M, Cobb CM, Rossmann JA, Spencer P. The effects of $\mathrm{CO} 2, \mathrm{Nd}: Y A G$ and Er:YAG lasers with and without surface coolant on tooth root surfaces - an in vitro study. Journal of Clinical Periodontology 1997; 24, 595-02.

16. Guidotti R, Merigo E, Fornaini C. Er:YAG 2,940-nm laser fiber in endodontic treatment: a help in removing smear layer. Lasers Med Sci 2014; 29:69-75.

17. DiVito E, Peters OA, Olivi G. Effectiveness of the erbium:YAG laser and new design radial and stripped tips in removing the smear layer after root canal instrumentation. Lasers Med Sci. 2012; 27(2):273-80.

18. Merigo E, Clini F, Fornaini C, Oppici A, Paties C, Zangrandi A, Fontana M, Rocca JP, Meleti M, Manfredi M, Cella L, Vescovi P. Laser-assisted surgery with different wavelengths: a preliminary ex vivo study on thermal increase and histological evaluation. Lasers Med Sci 2013; 28(2):497-504.

19. Bitter K, Paris S, Pfuertner C, Neumann K, Kielbassa AM. Morphological and bond strength evaluation of different resin cements to root dentin. Eur J Oral Sci 2009; 117:326-33.

20. Monticelli F, Ferrari M, Toledano M. Cement system and surface treatment selection for fiber post luting. Med Oral Patol Oral Cir Bucal 2008; 13: 214-21.

21. Piwowarczyk A, Bender R, Ottl P, Lauer HC. Long-term bond between dual-polymerizing cementing agents and human hard dental tissue. Dent Mater 2007; 23:211-7.

22. Faria M I, Sousa-Neto D M, Souza-Gabriel A E. Effects of 980-nm diode laser on the ultrastructure and fracture resistance of dentine. Lasers Med Sci 2013; 28:275-280. 